\title{
A Fractal-Like Kinetic Equation to Investigate Temperature Effect on Cellulose Hydrolysis by Free and Immobilized Cellulase
}

\author{
Yu Zhang • Jing-Liang Xu • Wei Qi • Zhen-Hong Yuan • \\ Xin-Shu Zhuang • Yun Liu $\cdot$ Min-Chao He
}

Received: 9 December 2010 / Accepted: 1 September 2011 /

Published online: 21 September 2011

(C) Springer Science+Business Media, LLC 2011

\begin{abstract}
According to fractal-like theory in the heterogeneous system, a cellulasecatalyzed kinetic equation that contained two parameters (rate constant $k$ and fractal dimension $h$ ) was deduced. The equation described directly the mathematical relationship between reducing sugar concentration and hydrolytic time, and accurately fitted the experimental data of free/immobilized cellulase at $37,40,44,47$, and $50{ }^{\circ} \mathrm{C}$ $\left(R^{2}>0.99\right)$. The fitted $h$ value is estimated as a constant $(0.6148)$ in these tested temperatures. The fitted $k$ value increased with temperature increase, and the relationship agreed with Arrhenius equation $\left(R^{2}>0.98\right)$. The fractal-like equation could predict accurately the experimental data at low temperature $34{ }^{\circ} \mathrm{C}$ for free/immobilized cellulase and high temperature $53{ }^{\circ} \mathrm{C}$ for immobilized cellulase, but the prediction at $53{ }^{\circ} \mathrm{C}$ for free cellulase was not accurate enough due to its lower stability than immobilized cellulase. The application of fractal-like theory in cellulase kinetics is successful.
\end{abstract}

Keywords Biomass · Cellulase · Fractal-like kinetics · Rate constant · Arrhenius equation · Simulation and prediction

\section{Introduction}

Conversion of lignocellulosic materials to reducing sugar gains more and more attention due to its large potential value in solving resource crisis and environmental pollution caused by fossil resource $[1,2]$. In order to achieve efficient conversion, cellulase is always involved in the process [3-5]. At present, cellulase production is relatively costly, which requires the enzyme to be used as full as possible in its related industrial applications [6,7]. Advances in this aspect partly depend on the development

Y. Zhang $\cdot$ J.-L. Xu $\cdot$ W. Qi $\cdot$ Z.-H. Yuan $(\bowtie) \cdot$ X.-S. Zhuang $\cdot$ Y. Liu $\cdot$ M.-C. He

Key Laboratory of Renewable Energy and Gas Hydrate, Guangzhou Institute of Energy Conversion, Chinese Academy of Sciences, No. 2, Nengyuan Road, Wushan, Tianhe, Guangzhou 510640, China e-mail: yuanzh@ms.giec.ac.cn 
of cellulase kinetics $[8,9]$. Structured cellulosic substrate and complicated synergic action of several cellulase components in a heterogeneous system determine that the enzymatic process is highly complex, rendering it difficult for mathematical modeling [10, 11]. It has been shown that the classical Henri-Michaelis-Menten equation is not suitable for the analysis of heterogeneous reaction because the rate constant was time variant and quasi-steady theory could not be applied in the reaction $[10,12]$.

Since enzymatic hydrolysis of insoluble cellulose can be thought as a onedimensional heterogeneous reaction along a cellulosic fiber chain, the reaction is fractal $[9,12]$. However, few papers about cellulase fractal kinetics have been reported recently $[9,13,14]$. The effect of enzyme loading, hydrolytic time, substrate concentration, and size distribution on cellulose hydrolysis was concentrated in the past proposed kinetic models [8-10, 15-22], but few papers concerned temperature effect on the enzymatic hydrolysis $[14,23]$. Temperature increase within certain range may raise the rate of enzymatic hydrolysis, and too high temperature could bring the enzymatic rate slowdown due to thermal inactivation or denaturation of cellulase protein [24]. Many kinetic parameters are still closely related to temperature. Therefore, temperature could be considered as a very valuable parameter for the enzymatic hydrolysis and kinetic study.

In this study, we used a fractal-like kinetics model to investigate temperature effect on enzymatic hydrolysis of alkali-pretreated rice straw. Kinetic properties of free and immobilized cellulase were also compared in this paper. During reaction, immobilized cellulase is as soluble as free enzyme.

\section{Experimental}

\section{Materials}

Crude cellulase powder was provided by Shanghai Bio Life Science \& Technology Co., Ltd. of China. The activity is $74.07 \mathrm{FPU} / \mathrm{g}$ (FPU is the activity unit of cellulase when filter paper is used as substrate), strictly assayed by the description of the Commission on Biotechnology of the International Union of Pure and Applied Chemistry [25].

Rice straw was obtained from a local farm in a local harvest and pretreated by alkali as others described [10].

Enzymatic Hydrolysis by Free and Immobilized Cellulase

For $72 \mathrm{~h}, 1.72 \mathrm{~g}$ crude cellulase powder and $12.50 \mathrm{~g}$ pretreated rice straw (about $10 \mathrm{FPU} / \mathrm{g}$ substrate) were incubated with $250 \mathrm{ml}$ acetate buffer $(0.2 \mathrm{~mol} / \mathrm{L}, \mathrm{pH} 5.0)$ at $120 \mathrm{rpm}$. Temperatures of $34,37,40,44,47,50$, and $53{ }^{\circ} \mathrm{C}$ were tested for different times. At each desired time, solution was taken out and the produced reducing sugar concentration was assayed by DNS (3,5-dinitrosalicylic acid) method [25].

Same amount of cellulase protein was immobilized on the smart polymer Eudragit L-100 by our previously optimized method [26]. Immobilized cellulase is a solubleinsoluble enzyme that could be soluble during reaction and becomes insoluble after reaction according to the $\mathrm{pH}$ adjustment $[27,28]$. The same hydrolytic reaction as described above was carried out when immobilized cellulase took the place of free cellulase. 
Model Development

Assume cellulase $(E)$ (grams per liter) consisting of several components to form a single combined effect on the hydrolysis of insoluble substrate $(S)$ (grams per liter), so the enzymatic hydrolysis could be described as follow:

$$
S \stackrel{E}{\longrightarrow} P
$$

where $P$ (grams per liter) is the produced reducing sugar. During heterogeneous reaction, rate constant is time dependent and decreases with time increase. To emphasize the dependence, rate constant is always assumed to be a power function of time $[12,13]$. Simultaneously, if the hydrolysis is considered as a pseudo first-order reaction, the enzymatic rate could be expressed as the following mathematical equation:

$$
\frac{\mathrm{d}[P]}{\mathrm{d} t}=k t^{-h}\left(\left[S_{0}\right]-0.9[P]\right)
$$

where $k$ and $h$ are empirical constants representing rate constant and fractal dimension, respectively [13]. 0.9 is the conversion coefficient from cellulose to reducing sugar. Phenomenologically and theoretically, $h$ value should be between 0 and 1 . In heterogeneous reaction, $0<h<1$ and $k$ is time dependent. When $h=0, k$ is time independent which indicates that it is a homogeneous reaction [12].

Integrating Eq. 3 with the boundary condition $([P]=0$, at $t=0)$ produces

$$
[P]=\frac{\left[S_{0}\right]}{0.9}\left[1-\exp \left(-\frac{0.9 k}{1-h} t^{1-h}\right)\right]
$$

Equation 3 is a fractal-like kinetic equation that expresses specific mathematical function between the product concentration $[P]$ and hydrolytic time $t$. Compared to many other models [16, 17, 21, 29-32], benefits of the model include an effective analytical solution, a good convergence for product formation, and simple equation (only two easily determined parameters).

\section{Results and Discussion}

Experimental Data of Enzymatic Hydrolysis

Table 1 showed the effect of temperature on the enzymatic hydrolysis of alkalipretreated rice straw by free and immobilized cellulase. The results pointed out that temperature increase could result in higher amount of reducing sugar due to rate acceleration by thermal energy increase of substrate. When temperature was over $44{ }^{\circ} \mathrm{C}$, small difference was observed probably due to contact saturation of the substrate thermal energy. For each temperature, the hydrolytic rate got to maximum value at the initial stage and gradually became lower and lower as time increased. Over 50\% production was produced within the first $10 \mathrm{~h}$ for each temperature. The slowdown for hydrolytic rate could be caused by enzyme inactivation, substrate recalcitrance, and product accumulation. Reducing sugar produced by immobilized cellulase was less than that by free cellulase at each temperature due to incompletely activity recycle from the immobilization [26, 33-35]. 
Table 1 Reducing sugar concentration produced from enzymatic hydrolysis of alkali-pretreated rice straw by free and immobilized cellulase at different temperatures

\begin{tabular}{|c|c|c|c|c|c|}
\hline Hydrolytic time $t(\mathrm{~h})$ & $37{ }^{\circ} \mathrm{C}$ & $40{ }^{\circ} \mathrm{C}$ & $44{ }^{\circ} \mathrm{C}$ & $47^{\circ} \mathrm{C}$ & $50{ }^{\circ} \mathrm{C}$ \\
\hline \multicolumn{6}{|c|}{ Reducing sugar concentration produced by free cellulase $(\mathrm{g} / \mathrm{L})$} \\
\hline 0 & 0 & 0 & 0 & 0 & 0 \\
\hline 1 & $7.12 \pm 0.30$ & $8.68 \pm 0.31$ & $8.96 \pm 0.33$ & $9.12 \pm 0.43$ & $11.52 \pm 0.33$ \\
\hline 3 & $10.54 \pm 0.46$ & $11.48 \pm 0.56$ & $12.46 \pm 0.40$ & $13.44 \pm 0.67$ & $14.49 \pm 0.61$ \\
\hline 6 & $13.31 \pm 0.52$ & $14.24 \pm 0.68$ & $15.64 \pm 0.49$ & $16.98 \pm 0.79$ & $16.72 \pm 0.71$ \\
\hline 9 & $15.18 \pm 0.32$ & $16.68 \pm 0.48$ & $18.08 \pm 0.78$ & $19.22 \pm 0.86$ & $20.72 \pm 0.96$ \\
\hline 12 & $16.66 \pm 0.71$ & $18.44 \pm 0.65$ & $19.89 \pm 0.91$ & $20.88 \pm 0.86$ & $21.36 \pm 0.76$ \\
\hline 24 & $20.64 \pm 0.85$ & $21.68 \pm 1.12$ & $24.22 \pm 1.08$ & $25.44 \pm 0.95$ & $26.16 \pm 1.25$ \\
\hline 30 & $22.04 \pm 1.19$ & $23.84 \pm 0.86$ & $25.96 \pm 1.24$ & $26.92 \pm 1.24$ & $27.24 \pm 1.33$ \\
\hline 36 & $23.28 \pm 0.94$ & $24.88 \pm 0.78$ & $27.24 \pm 1.22$ & $28.52 \pm 1.15$ & $28.64 \pm 1.41$ \\
\hline 48 & $25.22 \pm 1.22$ & $27.32 \pm 1.19$ & $29.54 \pm 1.41$ & $30.32 \pm 1.22$ & $31.68 \pm 1.36$ \\
\hline 60 & $26.78 \pm 1.24$ & $29.40 \pm 1.33$ & $30.50 \pm 1.24$ & $32.76 \pm 1.54$ & $33.72 \pm 1.16$ \\
\hline 71.5 & $28.04 \pm 1.28$ & $30.76 \pm 1.42$ & $33.10 \pm 1.40$ & $34.44 \pm 1.62$ & $36.28 \pm 1.55$ \\
\hline \multicolumn{6}{|c|}{ Reducing sugar concentration produced by immobilized cellulase (g/L) } \\
\hline 0 & 0 & 0 & 0 & 0 & 0 \\
\hline 1 & $6.22 \pm 0.20$ & $6.6 \pm 0.25$ & $7.32 \pm 0.33$ & $8.24 \pm 0.31$ & $9.44 \pm 0.45$ \\
\hline 3 & $9.34 \pm 0.41$ & $10.44 \pm 0.38$ & $11.00 \pm 0.42$ & $11.60 \pm 0.54$ & $12.72 \pm 0.48$ \\
\hline 6 & $11.82 \pm 0.39$ & $14.32 \pm 0.61$ & $15.16 \pm 0.52$ & $14.84 \pm 0.66$ & $15.16 \pm 0.74$ \\
\hline 9 & $13.56 \pm 0.52$ & $14.92 \pm 0.63$ & $16.32 \pm 0.77$ & $16.76 \pm 0.61$ & $16.92 \pm 0.45$ \\
\hline 12 & $15.28 \pm 0.67$ & $15.48 \pm 0.71$ & $16.72 \pm 0.52$ & $17.12 \pm 0.78$ & $18.68 \pm 0.81$ \\
\hline 24 & $18.52 \pm 0.82$ & $19.08 \pm 0.78$ & $20.88 \pm 0.95$ & $22.00 \pm 0.84$ & $22.60 \pm 0.67$ \\
\hline 30 & $19.96 \pm 0.99$ & $20.52 \pm 0.97$ & $22.60 \pm 1.01$ & $24.36 \pm 1.21$ & $26.20 \pm 1.08$ \\
\hline 36 & $21.18 \pm 0.79$ & $21.80 \pm 0.88$ & $24.72 \pm 1.08$ & $26.44 \pm 1.24$ & $27.72 \pm 1.23$ \\
\hline 48 & $22.92 \pm 1.11$ & $24.92 \pm 1.19$ & $27.04 \pm 0.93$ & $27.58 \pm 1.30$ & $28.76 \pm 1.22$ \\
\hline 60 & $24.32 \pm 1.09$ & $26.56 \pm 1.15$ & $28.44 \pm 1.31$ & $28.98 \pm 1.29$ & $29.98 \pm 1.10$ \\
\hline 71.5 & $25.78 \pm 1.28$ & $28.52 \pm 1.30$ & $30.20 \pm 1.41$ & $30.86 \pm 1.28$ & $31.52 \pm 1.40$ \\
\hline
\end{tabular}

Fractal-Like Kinetic Equation Based Fit

The experimental data of Table 1 were fitted into Eq. 3 by unary nonlinear regression for each temperature. Values of $k$ and $h$ determined from the fit were shown in Table 2. The

Table 2 Model parameters values determined from unary regression analysis of experimental data using Eq. 3

\begin{tabular}{lccccc}
\hline Temperature $T\left({ }^{\circ} \mathrm{C}\right)$ & \multicolumn{2}{l}{ Free cellulase } & & \multicolumn{2}{l}{ Immobilized cellulase } \\
\cline { 2 - 3 } \cline { 5 - 5 } \cline { 5 - 5 } & Rate constant $k$ & Fractal dimension $h$ & & Rate constant $k$ & Fractal dimension $h$ \\
\hline 37 & 0.05854 & 0.6186 & & 0.05151 & 0.6170 \\
40 & 0.06526 & 0.6158 & & 0.05630 & 0.6138 \\
44 & 0.07238 & 0.6120 & & 0.06241 & 0.6072 \\
47 & 0.07752 & 0.6112 & & 0.06561 & 0.6086 \\
50 & 0.08221 & 0.6243 & & 0.07017 & 0.6195 \\
\hline
\end{tabular}



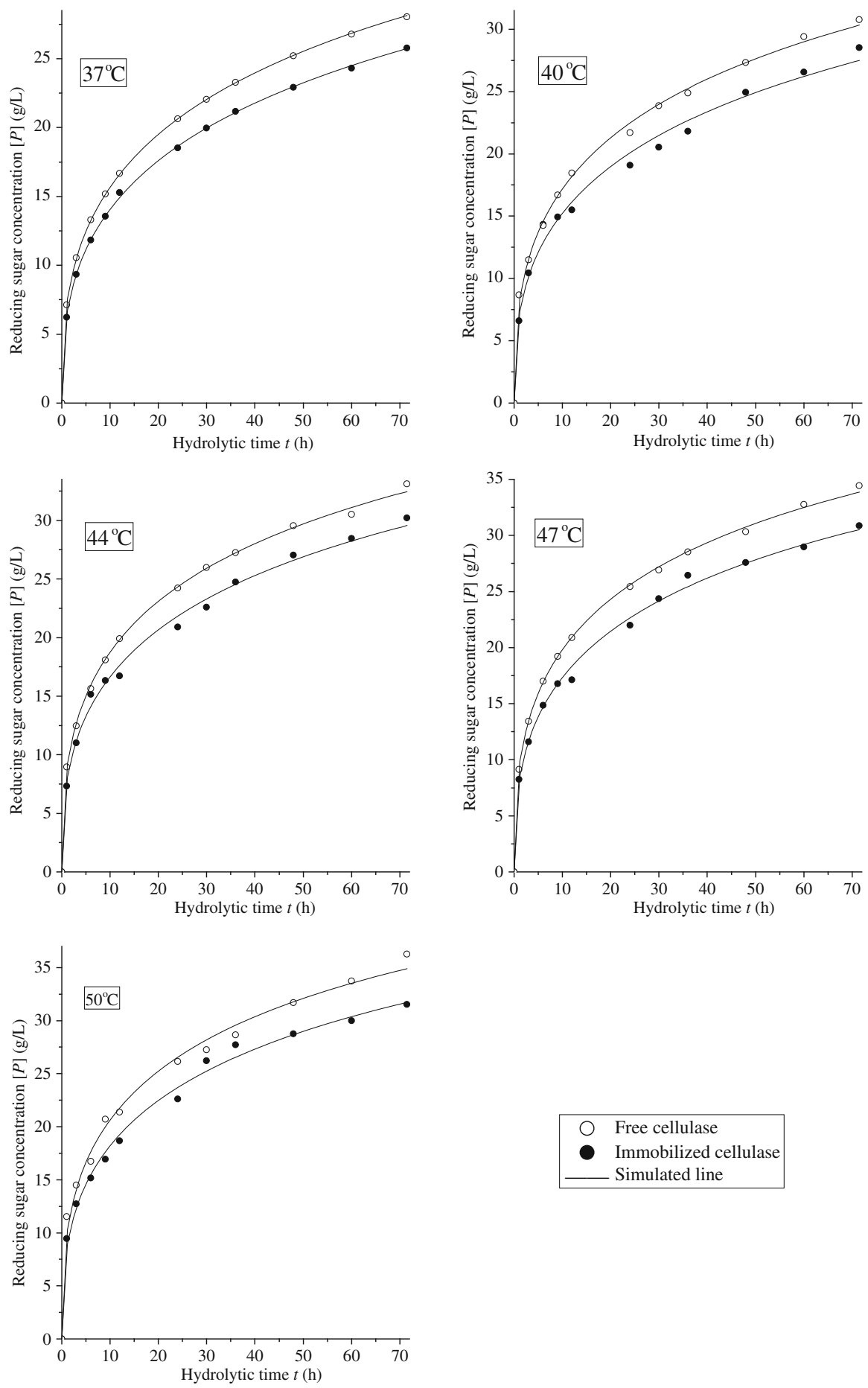

Free cellulase

- Immobilized cellulase Simulated line

Fig. 1 Reducing sugar concentration values simulated by Eq. 3 (continuous curves) versus experimental values (marker points) 
table stated clearly that $h$ value had little change and was between 0.60 and 0.63 at all temperatures for free and immobilized cellulase. From the physical point, $h$ is a quantitative parameter describing the substrate fractal [12]. It is only determined by substrate and not related to temperature and enzyme concentrations [13]. In our study, substrate and its concentration were invariable. So, $h$ should be a fixed-value parameter. The average $h$ value was calculated as 0.6148 .

We revised the fit using 0.6148 as the fixed $h$ value. The revised fitted results were shown in Fig. 1 and Table 3. Figure 1 represented the experimental points were rather close to the simulated curves by Eq. 3. On the whole, the fit accuracy for free cellulase was higher than that for immobilized cellulase. For free cellulase, some experimental points slightly deviated from the simulated curve only when temperature was $50{ }^{\circ} \mathrm{C}$. For immobilized cellulase, a little deviation all existed except when temperature was $37^{\circ} \mathrm{C}$. It could be observed from Table 3 that $k$ increased with the temperature increase. At any temperature, $k$ value of free cellulase was apparently larger than that of immobilized cellulase. The difference may be owed to its higher enzyme activity loading than immobilized cellulase. Immobilization could inevitably brought protein loss and enzyme inactivation $[11,33]$. Correlation coefficients $\left(R^{2}\right)$ were all above 0.99 which evidences that the fit was very perfect.

\section{Arrhenius Equation Based Fit}

In order to quantificationally illustrate the relationship between $k$ and temperature, Arrhenius equation was applied. Indefinite integral of Arrhenius equation could be described as follow:

$$
\ln k=-\frac{E_{\mathrm{a}}}{R} \frac{1}{T}+\ln A
$$

where $T$ (kelvin) is kelvin temperature, $R$ (joules per mole kelvin) is molar gas constant, $E_{\mathrm{a}}$ (kilojoules per mole) is activation energy, and $A$ is pre-exponential factor that represents the maximum limit value of rate constant when temperature approaches infinity high.

As shown in Fig. 2 (marker points), natural logarithm of $k(\ln k)$ and reciprocal of kelvin temperature $(1 / T)$ were taken as ordinate and abscissa, respectively. It could be found that these marker points similarly presented a linear relationship. Therefore, we considered that the relationship of $k$ and $T$ agreed with Arrhenius equation, and fitted the marker points by

Table 3 Rate constants and correlation coefficients from the revised fit based on Eq. 3 using fixed $h$ value (0.6148)

\begin{tabular}{|c|c|c|c|c|}
\hline \multirow[t]{2}{*}{ Temperature ${ }^{\circ} \mathrm{C}$} & \multicolumn{2}{|l|}{ Free cellulase } & \multicolumn{2}{|c|}{ Immobilized cellulase } \\
\hline & Rate constant $k$ & Correlation coefficient $R^{2}$ & Rate constant $k$ & Correlation coefficient $R^{2}$ \\
\hline 37 & 0.05838 & $>0.9999$ & 0.05142 & 0.9997 \\
\hline 40 & 0.06522 & 0.9979 & 0.05634 & 0.9913 \\
\hline 44 & 0.07252 & 0.9990 & 0.06276 & 0.9955 \\
\hline 47 & 0.07770 & 0.9994 & 0.06590 & 0.9966 \\
\hline 50 & 0.08177 & 0.9928 & 0.06996 & 0.9943 \\
\hline
\end{tabular}




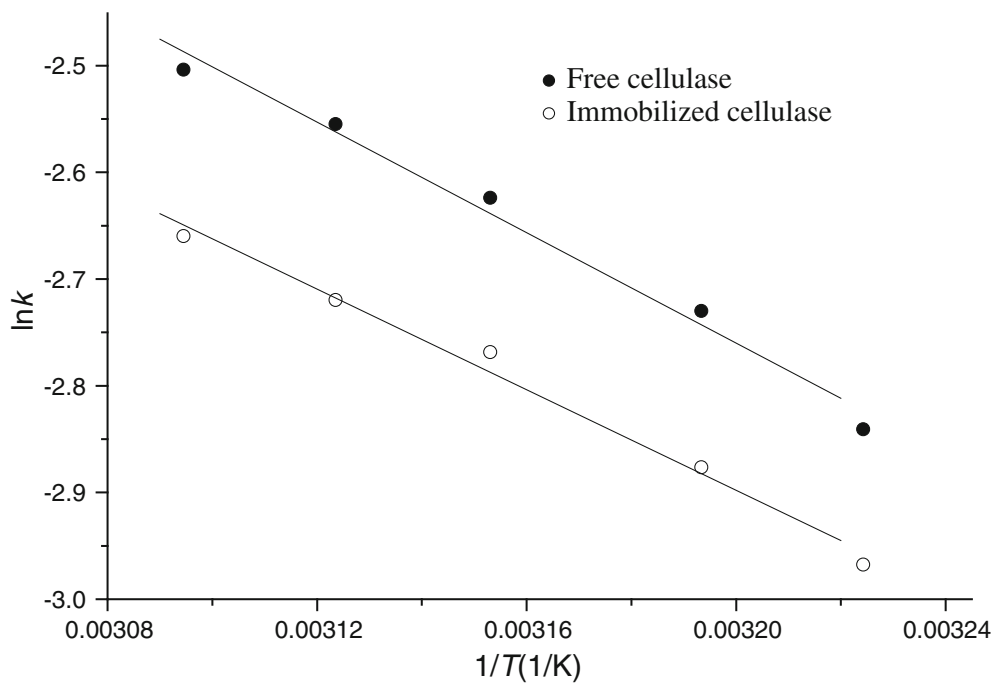

Fig. 2 Linear fit based on Arrhenius equation. Free cellulase: $y=-2,587.7344 x+5.5207\left(R^{2}=0.9859\right)$; immobilized cellulase: $y=-2,356.1596 x+4.6418\left(R^{2}=0.9891\right)$

linear regression analysis of $\ln k$ and $1 / T$. Fit results were shown in Fig. 3. Figure 3 indicated that the marker points were very close to the curve based Eq. 4 and the fit deviation was very small. Correlation coefficients $\left(R^{2}\right)$ were above 0.98 which evidences that the Eq. 4 based fit was very good.

According to Eq. 4, activation energy $\left(E_{\mathrm{a}}\right)$ and pre-exponential factor $(A)$ of free and immobilized cellulase was calculated (Table 4). $A$ of free cellulase is apparently higher than that of immobilized cellulase, and it is because activity loading in free cellulasecatalyzed experiments is higher than that in immobilized cellulase-catalyzed experiments. Noticeably, $E_{\mathrm{a}}$ of free cellulase is slightly higher than that of immobilized cellulase, which indicates that immobilized cellulase is more easily to catalyze the hydrolytic reaction. Similar results were obtained when Eudragit L-100 were used to immobilize other enzymes [36]. The difference may be attributed to affinity of enzyme to substrate.
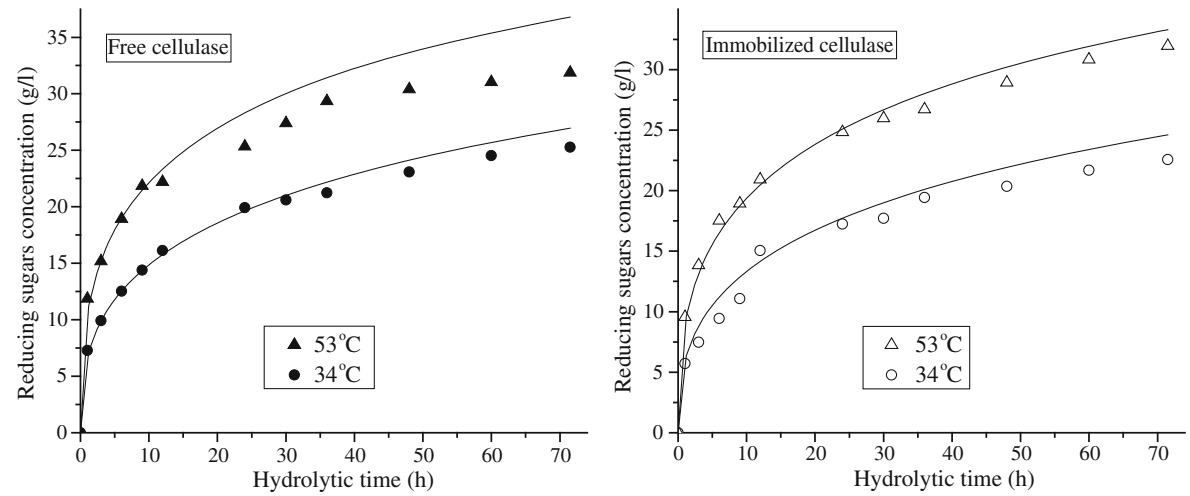

Fig. 3 Model predictive reducing sugar concentration values versus experimental values 
Via the immobilization, the affinity of enzyme to substrate could be improved as others demonstrated [36, 37]. It also has been reported that coupling enzyme to other smart polymers could improve the affinity [38-43].

$E_{\mathrm{a}}$ is the minimum required potential energy for conversion of the reactants to the activated complex. Theoretically, the higher the $E_{\mathrm{a}}$, the more difficult it is for the reaction to occur. However, when two easily hydrolyzed materials, namely carboxymethyl cellulose and cellulose film, were used as substrates for cellulase hydrolysis, the value of $E_{\mathrm{a}}$ is higher than that in our study [23, 44]. This is because the value of $E_{\mathrm{a}}$ calculated from Arrhenius equation is an apparent or empirical value, not a true practical value required for reaction start-up. The apparent $E_{\mathrm{a}}$ is relative and could only be compared at the same conditions.

\section{Model Prediction}

In order to examine the predictive performance of fractal-like kinetic model, four experiments were carried out. As shown in Fig. 3, selected temperatures were 34 and $53{ }^{\circ} \mathrm{C}$ (experimental results were shown as marker points). Substituting the values of $E_{\mathrm{a}}$ and $A$ in Table 4, Eq. 4 was used to calculate the corresponding $k$ values at the two temperatures (Table 4). Then, Eq. 3 was used to predict the experimental results using the $k$ values (continuous curves in Fig. 3 were the prediction based on Eq. 3).

Compared to the fit in Fig. 1, the predictive accuracy based on Eq. 3 was slightly low. However, it could still be considered that the prediction at $34{ }^{\circ} \mathrm{C}$ for free/ immobilized cellulase and at $53{ }^{\circ} \mathrm{C}$ for immobilized cellulase was successful. On the whole, the marker points were in accordance with the predictive curves and the deviation occurring under the conditions was not very significant. But larger deviation occurs for free cellulase when temperature was $53{ }^{\circ} \mathrm{C}$. It may be accounted for thermal inactivation or denaturation of free cellulase at high temperature, where the rate constant $k$ does not any longer increase with temperature increase. For immobilized cellulase, the thermal stability of cellulase was improved apparently [28, 35], so the prediction was still accurate.

\section{Conclusions}

Classical reaction kinetics has been found to be unsatisfactory for studying enzymatic hydrolysis of insoluble cellulose. In this paper, the application of a fractal-like kinetic model to investigate temperature effect on the enzymatic hydrolysis was successful. It is significant for further kinetic study. The fixed fractal dimension $h$ value was obtained from the model that could offer quantitative information about the alkali-pretreated rice straw. The rate constant $k$ of immobilized cellulase could increase within a wider temperature range than that of free cellulase, which further verified that the thermal stability of cellulase was improved via the immobilization.

Table $4 E_{\mathrm{a}}$ and $A$ values fitted from linear regression analysis of data in Table 2 using Eq. 4

\begin{tabular}{lcc}
\hline & $\begin{array}{l}\text { Activation energy } E_{\mathrm{a}} \\
(\mathrm{kJ} / \mathrm{mol})\end{array}$ & $\begin{array}{l}\text { Pre-exponential } \\
\text { factor } A\end{array}$ \\
\hline Free cellulase & 21.51 & 249.81 \\
Immobilized cellulase & 19.59 & 103.73 \\
\hline
\end{tabular}


Acknowledgments This work was funded by the Knowledge Innovation Program of the Chinese Academy of Sciences (KSCX-YW-11-A3) and National Key Technology R\&D Program (2011BAD22B01).

\section{References}

1. Gray, K. A. (2007). International Sugar Journal, 109, 145-151.

2. Jørgensen, H., Kristensen, J. B., \& Felby, C. (2007). Biofuels, Bioproducts and Biorefining, 1, 119-134.

3. Han, Y. J., \& Chen, H. Z. (2010). Biochemical Engineering Journal, 48, 218-224.

4. Sukumaran, R. K., Mekala, N. K., Singhania, R. R., \& Pandey, A. (2008). Applied Biochemistry and Biotechnology, 151, 122-131.

5. Zhang, J. A., Liu, Q., Cheng, K. K., Li, J. P., \& Wang, G. H. (2010). Applied Biochemistry and Biotechnology, 160, 604-612.

6. Zhuang, J., Marchant, M. A., Nokes, S. E., \& Strobel, H. J. (2007). Applied Engineering in Agriculture, 23, 679-687.

7. Zhang, Y. H. P., Himmel, M. E., \& Mielenz, J. R. (2006). Biotechnology Advances, 24, 452-481.

8. Shen, J. C., \& Agblevor, F. A. (2008). Biochemical Engineering Journal, 41, 241-250.

9. Bansal, P., Hall, M., Realff, M. J., Lee, J. H., \& Bommarius, A. S. (2009). Biotechnology Advances, 27, 833-848.

10. Carrillo, F., Lis, M. J., Colom, X., Lopez-Mesas, M., \& Valldeperas, J. (2005). Process Biochemistry, 40, 3360-3364.

11. Zhang, Y., Xu, J. L., Yuan, Z. H., Zhuang, X. S., \& Lu, P. M. (2009). Chinese Journal of Catalysis, 30, 355-358.

12. Kopelman, R. (1988). Science, 241, 1620-1626.

13. Valjamae, P., Kipper, K., Pettersson, G., \& Johansson, G. (2003). Biotechnology and Bioengineering, 84, 254-257.

14. Wang, Z. L., \& Feng, H. (2010). Bioresource Technology, 101, 7995-8000.

15. Gan, Q., Allen, S. J., \& Taylor, G. (2003). Process Biochemistry, 38, 1003-1018.

16. Liao, W., Liu, Y., Wen, Z. Y., Frear, C., \& Chen, S. L. (2008). Biotechnology and Bioengineering, 101, $441-451$.

17. Rotter, B. E., Barry, D. A., Gerhard, J. I., \& Small, J. S. (2008). Bioresource Technology, 99, 5738-5748.

18. Ai-Zuhair, S. (2008). Bioresource Technology, 99, 4078-4085.

19. Shen, J. C., \& Agblevor, F. A. (2008). Chemical Engineering Communications, 195, 1107-1121.

20. Shen, J. C., \& Agblevor, F. A. (2010). Applied Biochemistry and Biotechnology, 160, 665-681.

21. Zheng, Y., Pan, Z. L., Zhang, R. H., \& Jenkins, B. M. (2009). Biotechnology and Bioengineering, 102, $1558-1569$.

22. Zhang, Y., Xu, J. L., Xu, H. J., Yuan, Z. H., \& Guo, Y. (2010). Bioresource Technology, 101, 8261-8266.

23. Heitmann, J. A., Hu, G., \& Rojas, O. J. (2009). The Journal of Physical Chemistry. B, 113, 1476114768.

24. Demerdash, M., \& Attia, R. M. (1992). Zbl. Mikrobiol., 147, 477-482.

25. Ghose, T. K. (1987). Pure and Applied Chemistry, 2, 257-268.

26. Zhang, Y., Xu, J. L., Yuan, Z. H., Xu, H. J., \& Yu, Q. (2010). Bioresource Technology, 101, 3153-3158.

27. Taniguchi, M., Kobayashi, M., \& Fujii, M. (1989). Biotechnology and Bioengineering, 34, $1092-1097$.

28. Dourado, F., Bastos, M., Mota, M., \& Gama, F. M. (2002). Journal of Biotechnology, 99, $121-131$.

29. Turon, X., Rojas, O. J., \& Deinhammer, R. S. (2008). Langmuir, 24, 3880-3887.

30. Bommarius, A. S., Katona, A., Cheben, S. E., Patel, A. S., Ragauskas, A. J., Knudson, K., et al. (2008). Metabolic Engineering, 10, 370-381.

31. Xu, F., \& Ding, H. S. (2007). Applied Catalysis A: General, 317, 70-81.

32. Peri, S., Karra, S., Lee, Y. Y., \& Karim, M. N. (2007). Biotechnology Progress, 23, 626-637.

33. Mateo, C., Palomo, J. M., Fernandez-Lorente, G., Guisan, J. M., \& Fernandez-Lafuente, R. (2007). Enzyme and Microbial Technology, 40, 1451-1463.

34. Wang, Y. H., Zhang, J. C., \& Yin, J. M. (2009). Desalination Water Treatment, 1, 151-171.

35. Zhang, Y., Xu, J. L., Li, D., \& Yuan, Z. H. (2010). Biocatalysis and Biotransformation, 28, 313-319.

36. Rajoka, M. I., Zia, Y., \& Khalil-ur-Rehman. (2007). Protein and Peptide Letters, 14, 734-741.

37. Cong, L., Kaul, R., Dissing, U., \& Mattiasson, B. (1995). Journal of Biotechnology, 42, $75-84$.

38. Hoshino, K., Taniguchi, M., Netsu, Y., \& Fujii, M. (1989). Journal of Chemical Engineering of Japan, 22, 54-59.

39. Mondal, K., Mehta, P., Mehta, B. R., Varandani, D., \& Gupta, M. N. (2006). BBA-Proteins Proteomics, $1764,1080-1086$. 
40. Jain, S., Roy, I., \& Gupta, M. N. (2004). Artificial Cells, Blood Substitutes, and Immobilization Biotechnology, 32, 325-337.

41. Roy, I., \& Gupta, M. N. (2003). Biocatalysis and Biotransformation, 21, 297-304.

42. Sharma, S., Kaur, P., Jain, A., Rajeswari, M. R., \& Gupta, M. N. (2003). Biomacromolecules, 4, 330336.

43. Charusheela, A., \& Arvind, L. (2002). Enzyme and Microbial Technology, 30, 19-25.

44. Yao, S. Z., He, D. L., Bao, L. L., Long, Y. M., \& Wei, W. Z. (2000). Talanta, 50, 1267-1273. 